\title{
Endovascular stenting for descending aneurysms: Wave of the future or the emperor's new clothes?
}

\author{
John A. Elefteriades, MD, and Andrew Percy
}

See related article on page 369 .

From the Section of Cardiothoracic Surgery, Yale University School of Medicine, New Haven, Conn.

Received for publication Sept 24, 2006; accepted for publication Sept 28, 2006.

Address for reprints: John A. Elefteriades, MD, Section of Cardiothoracic Surgery, Yale University School of Medicine, 333 Cedar St (121 FMB), New Haven, CT 06510 (E-mail: john.elefteriades@yale.edu).

J Thorac Cardiovasc Surg 2007;133:285-8

$0022-5223 / \$ 32.00$

Copyright () 2007 by The American Association for Thoracic Surgery

doi:10.1016/j.jtcvs.2006.09.042 $\longrightarrow$ ardiothoracic surgeons owe a debt of gratitude to Bavaria and colleagues ${ }^{1}$ for spearheading these exciting clinical investigations into novel endovascular therapies for aneurysm disease from within the specialty of cardiothoracic surgery. This provides the opportunity for these investigations to be imbued with decades ${ }^{2}$ of collective wisdom from the perspective of cardiothoracic surgery. This also provides the opportunity for our specialty to continue leadership in the treatment of these diseases as technology advances.

The article by Bavaria and colleagues ${ }^{1}$ represents a large, multicenter comparative trial between traditional aortic surgery and endografting for descending thoracic aortic aneurysms. The study is well conceived and well presented and demonstrates satisfactory early performance of the endografts. This is very important work, vital to the advancement of the field, for which the investigators are to be congratulated.

It is extremely important to evaluate endograft therapy of aneurysms in organized clinical trials. Ultimately, randomized trials of thoracic endografts versus open surgical repair will be required for strongly based conclusions to be drawn.

It is important for medical science to evaluate endografting of aneurysms with enthusiasm for this new modality but, at the same time, with a grain of skepticism or at least realism. Multiple reasons to be cautious can be cited.

\section{Conceptual Issues}

First, some question the very concept of repair of an expanding cylindrical structure by means of a graft placed within its lumen. Stents, it is pointed out, were developed to keep arteries from closing in (as in coronary angioplasty), not to keep them from expanding outward. How can a graft placed inside an enlarging aorta and not attached to the aorta prevent the inexorable expansion of that aorta? Some say the graft would have to go outside, not inside, the aorta, a concept that was tried and failed many years ago. To control a herd of cattle, the analogy goes, the wooden pen has to go outside the cows; an internal endograft is like putting the pen inside the herd. The concern is that the inexorable expansion of the aorta will ultimately leave the endograft behind, ignoring it, so to speak. Another conceptual issue concerns continued pressurization of the aneurysmal sac by intercostals or lumbar vessels. Yet another conceptual issue concerns the surgeon's understanding that the strength of the aorta resides in the adventitia, which is not incorporated in any way by the endograft.

\section{Short Duration of Follow-up of an Indolent Disease}

This line of reasoning leads to the second major concern. Thoracic aortic aneurysm, although ultimately lethal, is an indolent disease. Many years are generally required from the time of diagnosis to the time of aneurysm-related death, especially with small- to moderate-sized aneurysms (Figure 1). ${ }^{3}$ To have patients alive at 1 or 2 


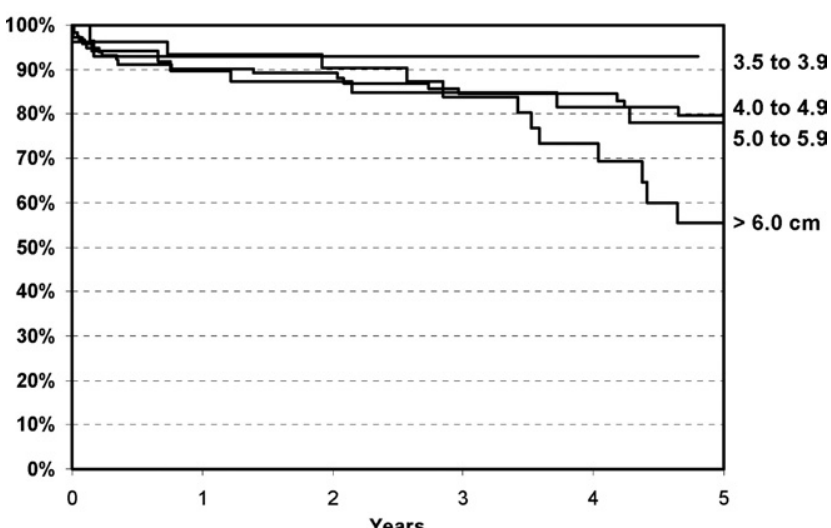

Figure 1. Indolent nature of thoracic aortic aneurysm. Survival before operative repair is shown for different size classes. Note that years generally pass before the mortality risk expresses itself, even for large aneurysms. Source: Coady MA, Rizzo JA, Hammond GL, et al. What is the appropriate size criterion for resection of thoracic aortic aneurysms? J Thorac Cardiovasc Surg. 1997;113:476-91. Reprinted with permission from Elsevier Inc.

years (mean follow-up is only 25.8 months in the present study) is not at all reassuring. These patients would probably still be alive absent any directed therapy whatsoever. As longer-term follow-up becomes available through the EUROSTAR investigation of endografting for abdominal

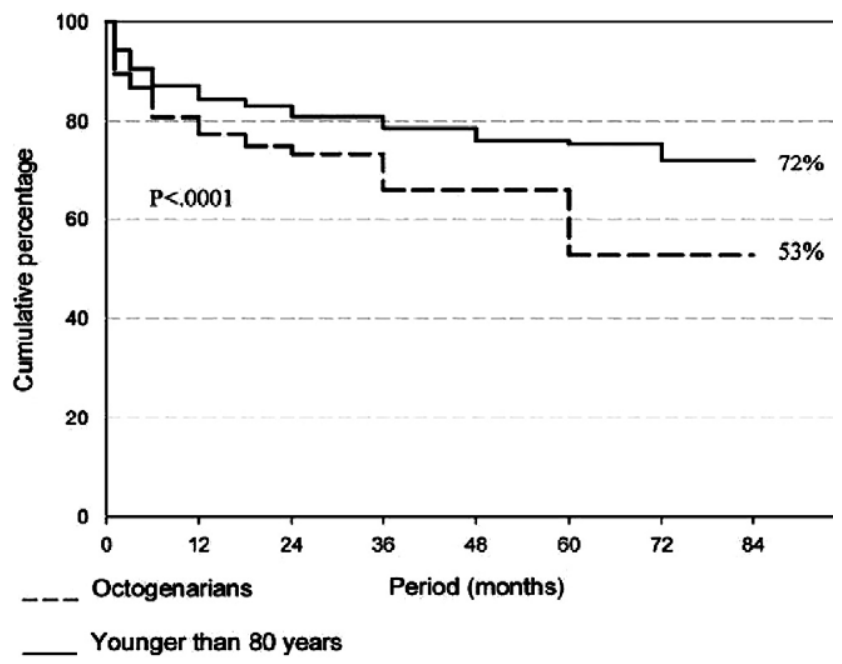

Figure 2. Kaplan-Meier graph representing cumulative freedom from any endoleak in patients operated on for abdominal aortic aneurysm with endovascular aneurysm repair. Source: Lange C, Leurs LJ, Buth J, et al. Endovascular repair of abdominal aortic aneurysm in octogenarians: an analysis based on EUROSTAR data. J Vasc Surg. 2005;42:624-30. Reprinted with permission from Elsevier Inc.

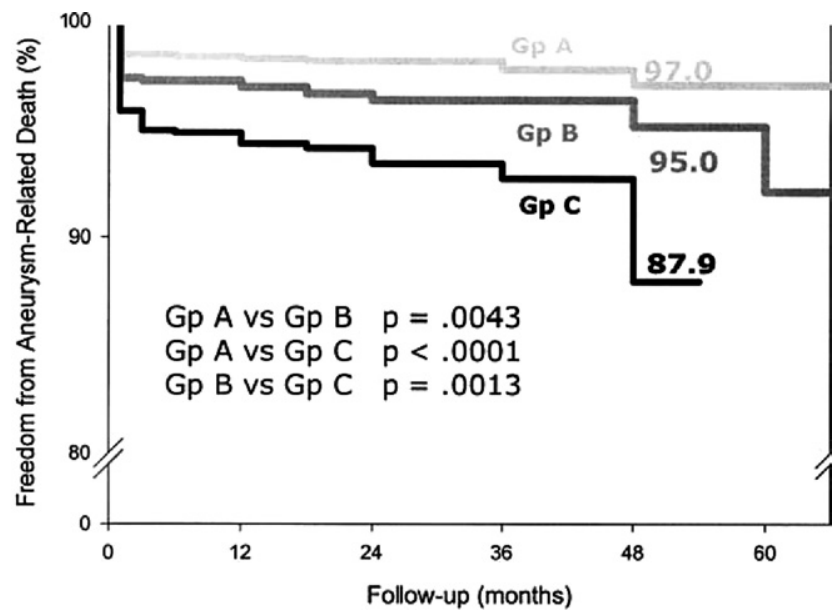

Figure 3. Cumulative freedom from aneurysm-related death. Note low attrition of survival in first 3 years of follow-up and rapid attrition in fourth year. Gp, Group. Groups represent increasing initial aneurysm size: group A, 4.0 to $5.4 \mathrm{~cm}$; group $B, 5.5$ to $6.4 \mathrm{~cm}$; group C, $6.5 \mathrm{~cm}$ or larger. Source: Peppelenbosch N, Buth J, Harris $\mathrm{PL}$, et al. Diameter of abdominal aortic aneurysm and outcome of endovascular aneurysm repair: does size matter? A report from EUROSTAR. J Vasc Surg. 2004;39:288-97. Reprinted with permission from Elsevier Inc.

aortic aneurysm, this concern literally comes to life, with mortality and rupture rearing their ugly heads as the aneurysm disease expresses its natural history, even after "successful" endografting. The EUROSTAR study of endografting for abdominal aortic aneurysms is much more mature than corresponding studies of thoracic aortic aneurysms. In Figure 2 it can be noted that endoleak becomes increasingly common as duration of follow-up is extended. ${ }^{4}$ It appears that nearly half of patients will experience diagnosed endoleak as follow-up becomes extended toward the 5-year point. In this context we need to keep in mind that the term endoleak is itself a euphemism for failure of treatment. It has been demonstrated that endoleak predicts the need for surgical conversion, rupture, and death, which in one EUROSTAR publication affected, respectively, 14\%, 13\%, and $27 \%$ of patients by 5 years after the procedure among patients presenting originally with large aneurysms; these are sobering statistics after endograft therapy. ${ }^{5}$ Also concerning is the emergence of substantial rates of aneurysmrelated death after endograft therapy when follow-up extends to 4 years, especially for large aneurysms. ${ }^{6}$ This is shown vividly in Figure 3; this figure suggests, in fact, that the aneurysm is indeed ignoring the endograft and merely expressing its natural tendency to rupture. In recognition of these sobering statistics, several major EUROSTAR publications end with serious cautions about endograft therapy, calling attention to concerns about the long-term effectiveness and safety: 
- "The high incidence of late secondary interventions is a cause for concern with regard to broad application of endovascular AAA repair, and emphasizes the need for lifelong surveillance."

- "Continuing need for surveillance for device related complications remains necessary."

- "... the durability of this technique is currently unknown, and continued use of registries should provide data from long-term follow-up ... . Only longduration studies can tell us whether this type of therapy really works-whether it prevents aneurysm growth and rupture and patient death."

- "The midterm outcome of large aneurysms after EVAR was associated with increased rates of aneurysm related death, unrelated death, and rupture.... This finding may justify reappraisal of currently accepted management strategies."

The encyclopedic Health Services Technology Assessment Text of the Guide to Clinical Preventive Services, 3rd edition, issued the following concluding statement on endografting: "Long-term complications, including AAA rupture ... may result in significant long-term morbidity and mortality." 10

In the context of these long-term concerns, the current study should be viewed as only an extended short-term investigation.

Aside from these general issues, some specific points about the study by Bavaria and colleagues and its findings deserve emphasis, so that the results can be taken in the appropriate context.

\section{Many Patients Lost to Follow-up}

One becomes especially concerned on noting that follow-up is complete for only $77 \%$ of the surgical group and $86 \%$ of the endograft group. How were these patients lost in the present computerized era? Was a Social Security Death Index survey run on all the names? The study is a very short one, with corporate funding. Why couldn't each and every patient be accounted for? What if the missing patients are missing because they are dead? Were that so, that would be very, very serious. What if they are missing because they had problems and sought care elsewhere? For a compact, well-funded study that depends on accurate information, the incompleteness of follow-up of this study is concerning; stated results should be viewed as approximate.

\section{Many Exclusions}

The host of study exclusions (mycotic aneurysms, unstable patients, rupture, acute or chronic dissection, and connective tissue disorder) is extremely broad. Although this makes for a relatively uniform study group, only the mildest subgroups of aneurysm disease are represented. The patients being studied are essentially those at the lowest natural risk from their disease. (In fact, the endograft group was statistically less symptomatic than the surgical group, which is further evidence of mild disease in the endograft-treated patients.) Also, we must remember that descending aneurysms, for reasons that are not clear, do not naturally rupture until they are about $1 \mathrm{~cm}$ larger than ascending aneurysms. ${ }^{3}$ This issue of relatively mild aneurysm disease in the stented patients compounds the concerns about incomplete follow-up and short follow-up; complete longterm follow-up will be needed to provide convincing evidence that these patients have benefited above and beyond the natural behavior of untreated aneurysms.

Multiple other specific issues were raised by the reviewers of this article:

- How exactly did one endograft patient have an aortoesophageal fistula?

- The criterion for postoperative renal failure is especially harsh (30\% increase in creatinine level) and seems innately biased against surgical intervention, where small and transient increases in creatinine levels are the rule rather than the exception.

- It is important to emphasize that paraplegia and paraparesis do occur with endografting. The authors have done a service by pointing out the high-risk settings for endograft-related paraplegia.

- Spinal drains were not used routinely in the surgical group. This is contrary to standard practice and biases against the surgical group.

- Why could the authors not define a much larger surgical control group, especially in a multi-institutional study such as this? Historical control subjects were accepted, making this question even more cogent.

- Indications for treatment are unclear. Were these dimensional? Were all saccular aneurysms treated?

- The increase in aneurysm size in 9 patients is concerning.

- According to Table E2, 16.6\% of the patients had cancer. One wonders how endograft therapy of predominantly low-risk aneurysms in these patients was justified.

Despite these multiple concerns regarding interpretation of this study, this investigation represents a bold venture into new territory with a promising, albeit unproved, lessinvasive modality of therapy. We are indebted to the investigators for this work. As the authors rightly point out in their concluding statements, it is essential that each patient who has received endograft therapy be followed vigilantly for possible deterioration or complications as time passes. Moreover, it is incumbent on our profession not only to follow individual patients closely but also to evaluate the durability of endograft therapy in general with a vigilant eye. Although the authors argue that a randomized study comparing surgical intervention and endografting would be "impossible," this argument is not convincing. We look 
forward to longer and more complete follow-up of these specific patients and to randomized studies in the future.

The authors of this important study have done groundbreaking clinical work, forging a very important initial foray into endograft treatment of thoracic aortic aneurysms and the evaluation of its early efficacy.

\section{References}

1. Bavaria JE, Appoo JJ, Makaroun MS, Verter J, Yu Z-F, Mitchell RS. Endovascular stent grafting versus open surgical repair of descending thoracic aortic aneurysms in low-risk patients: a multicenter comparative trial. J Thorac Cardiovasc Surg. 2006;133:369-77.

2. Cooley DA, DeBakey ME. Surgical considerations of intrathoracic aneurysms of the aorta and great vessels. Ann Surg. 1952;135:660-80.

3. Coady MA, Rizzo JA, Hammond GL, et al. What is the appropriate size criterion for resection of thoracic aortic aneurysms? J Thorac Cardiovasc Surg. 1997;113:476-91.

4. Lange C, Leurs LJ, Buth J, et al. Endovascular repair of abdominal aortic aneurysm in octogenarians: an analysis based on EUROSTAR data. J Vasc Surg. 2005;42:624-30.
5. Waasderp EJ, de Vries JP, Hobo R, et al. Aneurysm diameter and proximal aortic neck diameter influence clinical outcome of endovascular abdominal aortic repair: a 4-year EUORSTAR experience. Ann Vasc Surg. 2005;19:757-9.

6. Peppelenbosch N, Buth J, Harris PL, et al. Diameter of abdominal aortic aneurysm and outcome of endovascular aneurysm repair: does size matter? A report from EUROSTAR. J Vasc Surg. 2004; 39:288-97.

7. Laheij RJ, Buth J, Harris PL, Moll FL, Stelter WJ, Verhoeven EL. Need for secondary interventions after endovascular repair of abdominal aortic aneurysm. Intermediate-term follow-up results of a European collaborative registry (EUROSTAR). Br J Surg. 2000; $87: 1666-73$

8. Hobo R, Buth J, and the EUROSTAR investigators. Secondary interventions following endovascular abdominal aortic aneurysm repair using current endografts. A EUROSTAR report. J Vasc Surg. 2006; 43:896-902.

9. Leurs LJ, Bell R, Degrieck Y, et al. Endovascular treatment of thoracic aortic diseases: combined experience from the EUROSTAR and United Kingdom Thoracic Endograft registries. J Vasc Surg. 2004;40: 670-80.

10. Health Services/Technology Assessment Text (HSTAT). Guide to clinical preventative services, 3rd ed. Evidence Syntheses, formerly Systematic Evidence Reviews. National Library of Medicine and NCBI. Available at: hstat.nlm.nih.gov. Accessed September 24, 2006.

\section{ON THE MOVE?}

Don't miss a single issue of the journal! To ensure prompt service when you change your address, please photocopy and complete the form below.

Please send your change of address notification at least six weeks before your move to ensure continued service. We regret we cannot guarantee replacement of issues missed due to late notification.

\section{JOURNAL TITLE:}

Fill in the title of the journal here.

\section{OLD ADDRESS:}

Affix the address label from a recent issue of the journal here.

\section{NEW ADDRESS:}

Clearly print your new address here.

Name

Address

City/State/ZIP
COPY AND MAIL THIS FORM TO:

Elsevier Inc.

Subscription Customer Service

6277 Sea Harbor Dr

Orlando, FL 32887
OR FAX TO:

407-363-9661

OR E-mail:

elspcs@elsevier.com
OR PHONE:

800-654-2452

Outside the U.S., call

407-345-4000 